\title{
Práticas e percepçôes acerca do aleitamento materno: consensos e dissensos no cotidiano de cuidado numa Unidade de Saúde da Família*
}

I 'Emanuele Souza Marques, ${ }^{2}$ Rosângela Minardi Mitre Cotta, ${ }^{3}$ Sylvia do Carmo Castro

Franceschini, ${ }^{4}$ Maria Izabel Vieira Botelho, ${ }^{5}$ Raquel Maria Amaral Araújo, ${ }^{6}$ Túlio da Silva Junqueira I

Resumo: Este estudo fundamentou-se na pesquisa qualitativa, e teve um duplo objetivo: identificar o significado do aleitamento materno para os profissionais que atuam no PSF e evidenciar os temas convergentes e divergentes em relação à amamentação entre os profissionais de saúde e as nutrizes. Utilizou a entrevista semiestruturada e o grupo focal como técnica de coleta de dados. Ao todo, participaram 17 profissionais atuantes na atenção básica de saúde e 58 mães de crianças menores de dois anos de idade do município de Coimbra, MG. Entre os resultados mais relevantes, destacam-se: a amamentação foi vista como uma obrigação da mulher; o discurso profissional remete à necessidade de capacitação em aleitamento; a análise das falas permitiu evidenciar um verdadeiro descompasso entre o conhecimento relatado pelo profissional e a práxis cotidiana do serviço de saúde. Neste sentido, destaca-se a importância das políticas de educação continuada e permanente como elemento-chave na capacitação em amamentação, e importante indicador para o planejamento das ações de saúde em nível local.

> Palavras-chave: Aleitamento materno; nutriz; Programa de Saúde da Família.

\author{
${ }^{1}$ Mestre em Ciência da \\ Nutrição pelo Departamento de \\ Nutrição e Saúde, Universidade \\ Federal de Viçosa, Minas \\ Gerais. Endereço eletrônico: \\ emanuelesm@gmail.com. \\ 2 Doutora em Saúde Pública \\ pela Universidade de Valência, \\ Espanha; professora adjunta no \\ Departamento de Nutrição e \\ Saúde, Universidade Federal de \\ Viçosa, Minas Gerais. Endereço \\ eletrônico: rmmitre@ufv.br. \\ ${ }^{3}$ Doutora em Ciência pela \\ Universidade Federal de São \\ Paulo/Escola Paulista de \\ Medicina, São Paulo; \\ professora associada I no \\ Departamento de Nutrição e \\ Saúde, Universidade Federal de \\ Viçosa, Minas Gerais. Endereço \\ eletrôinico: sylvia@ufv.br. \\ ${ }^{4}$ Doutora em Sociologia pela \\ UNESP/Araraquara; professora \\ associada I no Departamento \\ de Economia Rural, \\ Universidade Federal de \\ Viçosa, Minas Gerais. Endereço \\ eletrônico: mbotelho@ufv.br. \\ ${ }^{5}$ Doutora em Saúde da Criança \\ e da Mulher pelo Instituto \\ Fernandes Figueira/Fiocruz; \\ professora adjunta no \\ Departamento de Nutrição e \\ Saúde, Universidade Federal de \\ Viçosa, Minas Gerais. Endereço \\ eletrônico: raraujo@ufv.br. \\ ${ }^{6}$ Mestre em Administração \\ Pública pelo Departamento de \\ Administração, Universidade \\ Federal de Viçosa, Minas \\ Gerais. Endereço eletrônico: \\ tuliojunqueira@gmail.com.
}




\section{Introdução}

A estratégia do Programa de Saúde da Família (PSF) representa, na conjuntura atual, a principal alternativa de reorganização da atenção primária à saúde no âmbito do Sistema Único de Saúde (SUS). O PSF incorpora princípios e diretrizes do SUS, como: universalização, descentralização, integralidade, equidade e participação social, reafirmando o propósito de mudança do modelo assistencial vigente, bem como seu papel de porta de entrada para os serviços de saúde (BRASIL, 2001). Além disso, o PSF está centrado na família, entendida e percebida a partir de seu ambiente físico e social, o que vem possibilitando às Equipes de Saúde da Família (ESF) uma compreensão ampliada do processo saúde-adoecimento e da necessidade de intervençôes que vão além das práticas de cura de doenças, privilegiando as ações de prevenção de agravos e enfermidades e de promoção da saúde (BRASIL, 2001). Sendo assim, o PSF é um cenário pertinente para a realização de estratégias em prol do aleitamento materno, que, segundo as Normas Operacionais da Assistência à Saúde, é uma ação fundamental para a promoção da saúde da criança (BRASIL, 2002a).

Reforçando a ideia de incentivar a amamentação no nível primário de atenção, em 1999 foi criada a Iniciativa Unidade Básica Amiga da Amamentação, e em 2001, os Dez Passos para o Sucesso da Amamentação na Atenção Básica à Saúde, com o intuito de promover, proteger e apoiar de forma adequada o aleitamento materno no contexto local (OLIVEIRA, 2008).

Em 2006, o Ministério da Saúde lançou o Pacto pela Saúde, que redefine as responsabilidades de cada esfera governamental (União, estados e municípios) em função das demandas e necessidades de saúde da população (BRASIL, 2008a). Mais especificamente em relação à amamentação, o pacto pela saúde se propõe a (1) produzir e distribuir material educativo enfocando o aleitamento materno; (2) desenvolver campanhas para a orientação e sensibilização da população sobre os benefícios da amamentação; (3) sensibilizar os trabalhadores em saúde quanto à importância e aos benefícios da amamentação; (4) articular e mobilizar setores públicos e privados para a adoção de ambientes favoráveis ao aleitamento materno (BRASIL, 2006).

O leite humano oferece benefícios para o bebê, a mãe, a família e o Estado, em virtude de suas propriedades nutricionais, imunológicas e fisiológicas; e devido ao baixo custo, à praticidade e ao estímulo do vínculo mãe-filho (BRASIL, 2002b). 
Contudo, apesar de conhecidas as vantagens da amamentação, os índices de aleitamento materno estão aquém dos padrões recomendados pelos organismos nacionais e internacionais (BRASIL, 2008b). Nessa perspectiva, vários fatores contribuem para a baixa prevalência da amamentação, entre eles a dificuldade de acesso a serviços e profissionais de saúde qualificados e capacitados para o atendimento da mulher-mãe e da criança, principalmente no período pós-parto (SILVA, 2000).

Segundo Nakano et al. (2007, p. 231), “as informações e as práticas inadequadas dos profissionais de saúde têm influência negativa no estabelecimento e manutenção do aleitamento materno". Além disso, o reducionismo biológico e os mitos relacionados à amamentação também são encontrados na prática profissional, o que dificulta a adesão à prática de lactação (LANA; LAMOUNIER; CÉSAR, 2004; NAKANO et al., 2007). Logo, o acolhimento da mulher que amamenta pelos profissionais de saúde é fundamental para a empatia e, consequentemente, para a formação de vínculo, o qual permitirá a nutriz relatar suas queixas, dúvidas, medos e anseios vivenciados durante o aleitamento materno, assegurando uma atenção mais resolutiva a favor da amamentação (BRASIL, 2005).

Nesse sentido, este estudo tem dois objetivos. O primeiro é identificar o significado do aleitamento materno para os profissionais que atuam no PSF; e o segundo é evidenciar os temas convergentes e divergentes em relação à amamentação entre os profissionais de saúde e as nutrizes, de maneira a conhecer possíveis falhas de comunicação entre estes atores que possam levar ao insucesso do aleitamento materno.

\section{Metodologia: caracterização da área de estudo e dos serviços sanitários}

A pesquisa foi realizada no município de Coimbra - MG, localizado na mesorregião da Zona da Mata. Segundo o Instituto Brasileiro de Geografia e Estatística (IBGE), a população estimada de Coimbra para 2007 era de 6.886 habitantes, distribuída em $107 \mathrm{~km}^{2}$ de área territorial (IBGE, 2008).

Em relação às unidades de saúde existentes no município, de acordo com dados da Secretaria Municipal de Saúde, existe atualmente, na cidade de Coimbra, um Centro Municipal de Saúde que oferece serviços de vacinação, curativos, farmácia, consultas médicas e de emergência, dentre outros; e uma Unidade do PSF, que conta com duas Equipes de Saúde da Família, sendo que uma atende à zona rural e a outra, à urbana. 


\section{Desenho do estudo}

Trata-se de um estudo transversal, descritivo, com abordagem quanti-qualitativa. Utilizou-se o referencial teórico metodológico da pesquisa quantitativa para complementar o da pesquisa qualitativa - referencial instrumental primordial deste trabalho - devido às características do objeto de investigação e dos objetivos da pesquisa, como forma de captar a realidade dinâmica e complexa em sua realização histórico-social, em conformidade com os pressupostos teóricos que a orientam (MINAYO, 1994; SOUZA et al., 2005).

Dentro desta lógica, optou-se também pela utilização de diferentes instrumentos para a coleta de dados - triangulação de métodos - visando ao aprofundamento e à abrangência da compreensão, bem como a verificação e a validação da pesquisa (MINAYO, 2005; 2006).

O estudo foi realizado no período de outubro a dezembro de 2007 , sendo que a coleta de dados foi realizada em duas etapas: primeiramente, os dados foram coletados por meio de entrevistas semiestruturadas realizadas no local de trabalho ou no domicílio dos entrevistados. As entrevistas foram gravadas, após consentimento dos informantes, e transcritas. Em um segundo momento, foi realizado um grupo focal. Nesta técnica de pesquisa, o pesquisador reúne em um mesmo local e durante certo período uma determinada quantidade de pessoas que fazem parte do público-alvo de suas investigaçôes, tendo como objetivo obter - a partir do diálogo e do debate - os conceitos, impressões e concepções sobre um tema específico (MINAYO, 1994), neste caso, o aleitamento materno.

Ressalta-se que os debates foram registrados - através de gravadores e anotações referentes à linguagem verbal e não-verbal dos participantes - e posteriormente transcritos. Para a realização do grupo focal, contou-se com a presença de um facilitador e um cofacilitador.

Com o intuito de facilitar a caracterização da amostra, optou-se por distribuir os atores em três grupos: A, B e C. Compuseram o Grupo A ( $n=17)$ - 94,4\% - os profissionais do PSF: dois médicos, dois enfermeiros, dois técnicos em enfermagem e 11 agentes comunitários de saúde (ACS). Ressalta-se que apenas um ACS não 
foi entrevistado por motivo de recusa. Já o grupo B ( $n=15)$ - 68,2\% - foi formado pelos profissionais de saúde do município que participaram do grupo focal, entre os quais um enfermeiro, 12 ACS, um auxiliar de dentista e um nutricionista do município. O grupo C ( $\mathrm{n}=58)$ - 31,72\% - foi formado pelas mães de crianças menores de dois anos de idade residentes no município de Coimbra.

Após leitura global e detalhada das respostas dos entrevistados, passou-se para a análise de conteúdo, que compreendeu os seguintes momentos: (1) pré-análise; (2) ex;ploração do material; e (3) tratamento dos resultados, inferência e interpretação (BARDIN, 1977; MINAYO, 2006).Os dados quantitativos, referentes ao perfil dos entrevistados, foram analisados utilizando-se o software Statistical Package for the Social Sciences (SPSS) for Windows, versão 15.0.

Conforme Resolução no 196/96 do Conselho Nacional de Saúde, o projeto de pesquisa foi aprovado pelo Comitê de Ética em Pesquisa com Seres Humanos da Universidade Federal de Viçosa (Of.Ref.No 023/2007 de 24/05/2007).

\section{Resultados e discussão}

Alguns dados quantitativos serão brevemente apresentados para a caracterização dos grupos estudados. Em relação aos profissionais entrevistados (Grupo A), a maioria era do sexo feminino (94,1\%). A média de idade foi de 31,09 $\pm 9,29$ (mediana: 31 anos, mínimo: 18; máximo: 50 anos). Em relação à escolaridade, 23,5\% tinham o ensino médio incompleto; $23,5 \%$, o ensino médio completo; $11,8 \%$, o nível técnico completo; $11,8 \%$, o nível superior incompleto e 29,4\%, o nível superior completo; destes, dois cursavam pós-graduação lato sensu e um já havia concluído a pós-graduação - sendo que este era ACS.

Quanto ao estado civil, 52,9\% dos profissionais eram solteiros, 41,2\% eram casados e 5,9\% viviam em comunhão livre. Dos entrevistados, 29,4\% tinham filhos, sendo que $80 \%$ afirmam que seus filhos foram amamentados. Em relação à capacitação em aleitamento materno, $82,4 \%$ relataram não ter recebido nenhum curso específico sobre o assunto. 
Já dos profissionais que participaram do grupo focal (Grupo B), 80\% foram entrevistados individualmente. Os 20\% restantes ( $n=3$ ), isto é, profissionais do grupo focal que não foram entrevistados, em relação à escolaridade, $66,7 \%$ tinham o ensino superior completo e 33,3\% o nível técnico completo. Quanto ao estado civil, 100\% dos profissionais eram solteiros. Em relação à capacitação em aleitamento materno, $66,7 \%$ relataram não ter recebido nenhum curso específico sobre o assunto.

Das 58 mães entrevistadas (Grupo C), 10,3\% eram adolescentes (faixa etária de 16 a 19 anos), e 5,2\% tinham mais de 35 anos; a média de idade materna foi de 25,29 \pm 5,41 anos (mínimo: 16 anos; máximo: 37 anos). A maioria, 56,9\%, apresentava menos de oito anos de estudo e apenas 1,7\% possuía o ensino superior completo. Em relação ao estado civil, $51,7 \%$ das mulheres entrevistas eram casadas, $32,8 \%$ viviam em comunhão livre, $13,8 \%$ eram solteiras e 1,7\% eram divorciadas.

Quanto à ocupação, as mães entrevistadas em sua maioria eram donas de casa $(82,8 \%)$. Já a renda familiar, a média de ganho mensal era de $\mathrm{R} \$ 504,25$ (mínimo: $\mathrm{R} \$ 85,00$; máximo: $\mathrm{R} \$ 1.425,00$ ). Ressalta-se que a mediana da renda familiar mensal foi de $\mathrm{R} \$ 380,00$ (um salário mínimo de referência no período em que ocorreu o estudo).

No que se refere ao posicionamento frente à amamentação, este foi descrito pelos profissionais entrevistados como: ótimo, importante, fundamental e essencial, sendo que os relatos sobre as vantagens do aleitamento materno para a criança vinham sempre em primeiro lugar:

A criança que amamenta, ela é mais saudável, não tem problema de gripe, não tem problema de desnutrição. É... tá sempre com o peso normal. (Profissional 3).

[...] além de ser a primeira vacina da criança, né, ele [o leite materno] tem todos os anticorpos que a criança tem que receber assim... pra ela ficar protegida mesmo, né, de todos os problemas de saúde que eles possam vir a ter... (Profissional 4)

Acho que é, no mais popular mesmo, indispensável pra saúde da criança - mental, física, tudo... (Profissional 14).

Analisando os depoimentos, observou-se que o ato de aleitar foi considerado importante para o bebê, por proporcionar boas condiçôes de saúde, prevenir 
doenças, além de proteger a criança devido à imunidade conferida pelo leite materno - a primeira vacina do bebê. No presente estudo foi observado, também, que o amamentar aparece como uma obrigação da mulher enquanto ser mãe, conforme ilustram as falas que se seguem:

Ah! Eu acho que todas as mães devem amamentar... (Profissional 1).

Nossa... acho que o aleitamento é a primeira coisa que a mãe tem que pensar..."

(Profissional 4).

É a única coisa que a mãe tem que fazer [risos]. (Profissional 6).

Ainda no que concerne à opiniāo dos profissionais em relação à lactação, apreenderam-se dos relatos representações relacionadas ao baixo custo desta prática, considerada pelos entrevistados de suma importância, uma vez que, segundo os mesmos, a população atendida apresenta baixo nível scioeconômico:

[O leite] é de graça, não paga nada, né! (Profissional 1).

O leite materno também é barato, porque não custa dinheiro... (Profissional 11).

$\mathrm{Na}$ vivência cotidiana do profissional de saúde, ações verticalizadas e normatizadas, bem como o reducionismo biológico, se fazem presentes, negligenciando outras facetas inerentes ao processo saúde-doença, tais como os aspectos histórico, social e cultural (NAKANO et al., 2007; MONTEIRO, 2000).

Os profissionais de saúde constroem sua assistência à nutriz através dos significados por eles atribuídos à lactação - sendo a crença na amamentação como um ato instintivo e biológico - o elemento mais forte na construção desse atendimento (SILVA, 2001). Esses resultados vão ao encontro dos estudos desenvolvidos por Ramos e Almeida (2003) e Nakano (2003), no qual o significado da amamentação aparece pautado na possibilidade de a mãe dar o melhor para o bebê, ou seja, uma condição emblemática de ser uma boa mãe.

Há que se salientar, todavia, que os discursos produzidos pelos profissionais estudados estão alicerçados subliminarmente pelo modelo higienista, que tem como premissas o ato de amamentar como responsabilidade exclusiva da mulher enquanto protagonista da amamentação, bem como o aleitamento materno visto apenas sob a ótica das vantagens para o bebê (ALMEIDA, 1999). Ressalta-se, então, a importância de o profissional de saúde perceber sua importância como coadjuvante 
e cúmplice da mulher-mãe durante o puerpério e a amamentação (SOUZA, 2004), escutando e fornecendo informações, orientações e conselhos à nutriz sobre o aleitamento materno, de maneira que o cuidado transcenda o aspecto biológico, abrangendo dimensões sociais e culturais.

Quando questionados se consideravam capacitados para orientar as mães coimbrenses sobre a prática correta de lactação, os profissionais de saúde apontaram a necessidade de capacitação, bem como de esclarecimentos referentes às questões relacionadas à práxis cotidiana. Não obstante, a maioria dos profissionais entrevistados salientou que eles conseguiam passar para as mulheres atendidas um conhecimento básico sobre a amamentação:

É... pelo que a gente anda lendo, o que a gente leu, acho que... dá pra dar uma noção pra mãe, né, do que é o aleitamento, qual a importância, né, quais os benefícios que traz pra criança. Acho que o básico dá pra gente orientar. (Profissional $4)$.

Eu acho que... o pouco que a gente sabe, já tá passando pra ela e ajuda um pouco, né! (Profissional 6).

Outra questão importante encontrada neste estudo se refere ao fato de que grande parte dos conhecimentos repassados pelos profissionais coimbrenses às mães foi obtida através da sua vivência, como mãe, ou da observação de mães da comunidade na qual vivem e/ou trabalham, o que aponta para uma falha na capacitação e educação desses profissionais:

Eu acho que... [risos]. Eu acho que eu fiz tudo direitinho... como me ensinaram com o meu e eu tô passando pra frente. (Profissional 5).

Oh! O que eu sei foi geralmente assim... de experiência de pessoas que passaram pra mim. (Profissional 12).

Cabe destacar, ainda, que alguns profissionais de saúde coimbrenses informaram não se considerar capacitados para orientar a mulher durante o período de lactação, devido ao fato de não terem vivenciado a maternidade e a amamentação, o que reforça o achado apontado por este estudo, da necessidade de implementação de política de capacitação profissional voltada para a prática do aleitamento materno: 
Olha, eu considero sim em termos. Eu não tenho muita experiência porque eu não tenho filhos... (Profissional 1).

\begin{abstract}
Isso é o que eu falo, porque eu não sei, eu não tenho experiência nenhuma [risos]. (Profissional 2).

[...] porque eu não fui mãe, eu não tenho experiência nenhuma com isso ainda e por isto que eu não tenho preparo, eu não sei mesmo. (Profissional 8).

Eu acho, eu não sou mãe, eu não posso falar muita coisa, eu não tenho muita experiência... (Profissional 9).
\end{abstract}

No presente estudo, verificou-se que os profissionais seguem mais a sua experiência de mãe ou aquela adquirida da observação de outras mães, não se baseando nos conhecimentos científicos - o que seria o ideal, fato este também observado nos estudos de Monteiro (2000) e Souza (2004). Segundo Silva (2001, p. 10), o profissional de saúde acredita que

a visão das mulheres sobre o amamentar, é construída em experiências de amamentação vivenciadas por ela própria ou captadas em seu contato social com outras mulheres, bem como aquelas experiências que fazem parte do repertório familiar, que o profissional interpreta, como potencialmente positivas ou negativas.

Vale ressaltar que a não-vivência da maternidade e da amamentação não "desqualifica" o profissional que trabalha com mulheres-mães, principalmente se este estiver capacitado nestas temáticas (MONTEIRO, 2000). Os resultados apontados neste trabalho vão ao encontro da assertiva de Becker (2001, p. 77): "de nada adianta um profissional consciente da importância da amamentação e atuante em sua promoção se o mesmo fornecer informações erradas às mães ou se não souber apoiá-las em manejos adequados".

Contudo, os profissionais coimbrenses demonstram em seus depoimentos a necessidade de adquirir um embasamento teórico mais aprofundado em torno do aleitamento materno, resultado semelhante ao encontrado por Ciconi, Venâncio e Escuder (2004). Este fato remete à importância da implementação de políticas de capacitação e educação permanente em amamentação para o desenvolvimento de ações mais resolutivas a favor do aleitamento.

De acordo com Caldeira et al. (2007) e Silva, Araújo e Bittencourt (2008), faz-se necessário o investimento contínuo na sensibilização e capacitação dos profissionais sobre esta prática, de maneira a melhorar os índices de amamentação. 
Para isso, é de fundamental importância os cursos de aperfeiçoamento, atualização e de educação continuada, com intuito de formar profissionais comprometidos com a atual política de promoção, proteção e apoio ao aleitamento materno.

Quanto às principais queixas das mulheres atendidas no PSF de Coimbra durante o puerpério, segundo os profissionais entrevistados, a maioria dos depoimentos se refere às questôes relacionadas ao bebê, tais como: dor de barriga nos primeiros meses de vida e dificuldade de dormir a noite devido às mamadas noturnas, conforme ilustram os depoimentos que se seguem:

Criança chorando muito e não deixa dormir... [pausa]. Dor de barriga da criança, né! (Profissional 3).

É rachadura no peio, criança tem dificuldade de pegar o peito... criança mama muito à noite... [pausa]. Reclamam de muita coisa... dor de barriga que em até três meses. (Profissional 5).

Além disso, os profissionais relataram que as nutrizes coimbrenses se queixavam de intercorrências mamárias e da qualidade/quantidade do leite por elas produzido, conforme se ilustra nas falas que se seguem:

Ah! Em relação à amamentação... porque dói muito, né! Fica muito tempo acordada a noite com o nenê... troca o dia pela noite... a noite pelo dia... ou o dia pela noite? Acorda de dez em dez minutos, tá acordada... quer mamá... elas acham que o leitinho não tá sustentando... (Profissional 1).

Que o peito dói, não sei que lá... mas logo na primeira semana, geralmente, a pessoa tem aquelas moléstias: dor no peito... mas isso é uma questão de costume... passou aquela semana de adaptação... porque geralmente fere mesmo! Então... dá uma sensação de dor, mas depois passa.. (Profissional 4).

Pra mim elas reclamam mais, geralmente, que o leite é fraco. (Profissional 15).

Ainda como forma de ampliar o olhar sobre o fenômeno da amamentação, foram perguntadas aos profissionais de saúde e mães questões similares sobre o aleitamento materno. Outrossim, o presente estudo questionou as mães coimbrenses se elas haviam recebido orientações durante o puerpério e que orientações receberam; aos profissionais, foi perguntado se haviam realizado alguma orientação as gestantes e nutrizes e quais foram os temas contemplados. A síntese destes resultados está disposta na tabela 1 . 
Tabela 1: Temas convergentes e divergentes entre os membros da equipe do Programa de Saúde da Família e as nutrizes de Coimbra - MG, 2007

\begin{tabular}{|c|c|c|c|}
\hline Temas & $\begin{array}{c}\text { Profissionais de saúde } \\
\text { (Entrevistas) }\end{array}$ & $\begin{array}{c}\text { Profissionais de saúde } \\
\text { (Grupo Focal) }\end{array}$ & Nutrizes \\
\hline $\begin{array}{l}\text { Opinião sobre a } \\
\text { amamentação }\end{array}$ & $\begin{array}{l}\text { Enfoca, principalmente, os } \\
\text { benefícios para o bebê. } \\
\text { Considera a amamentação um } \\
\text { dever materno. } \\
\text { Importante do ponto de vista } \\
\text { econômico. }\end{array}$ & $\begin{array}{l}\text { Aspecto não abordado no } \\
\text { grupo focal }\end{array}$ & $\begin{array}{l}\text { Enfoca, principalmente, os benefícios para } \\
\text { o bebê. } \\
\text { Através dos relatos, observou-se que as } \\
\text { mães que não conseguiram aleitar seus } \\
\text { filhos se sentem frustradas e ao mesmo } \\
\text { tempo culpadas por năo terem se } \\
\text { esforçado mais para amamentá-lo. }\end{array}$ \\
\hline $\begin{array}{l}\text { Opinião sobre } \\
\text { o uso de } \\
\text { chupetas }\end{array}$ & $\begin{array}{l}\text { A maioria não recomenda o uso } \\
\text { de chupeta. } \\
\text { Contudo, alguns profissionais } \\
\text { acreditam que a chupeta auxilia a } \\
\text { nutriz, pois acalma a criança, } \\
\text { principalmente na hora do choro, } \\
\text { e permite que a mulher realize } \\
\text { outras atividades. }\end{array}$ & $\begin{array}{l}\text { A maioria năo recomenda o uso } \\
\text { de chupeta. }\end{array}$ & $\begin{array}{l}\text { Apesar de serem orientadas para năo } \\
\text { oferecer chupeta e de conhecerem os } \\
\text { malefícios da utilizaçăo deste objeto, a } \\
\text { maioria das măes tentou dar ou deu } \\
\text { chupeta para seu filho. } \\
\text { Os motivos para a utilização deste objeto } \\
\text { pelas mães foram por acalentar, acalmar a } \\
\text { criança, principalmente durante o choro. }\end{array}$ \\
\hline $\begin{array}{l}\text { Opinião sobre } \\
\text { o uso de } \\
\text { mamadeiras }\end{array}$ & $\begin{array}{l}\text { A maioria não recomenda o uso } \\
\text { de mamadeira. }\end{array}$ & $\begin{array}{l}\text { A maioria não recomenda o uso } \\
\text { de mamadeira. } \\
\text { Contudo, alguns profissionais } \\
\text { de saúde, principalmente os } \\
\text { ACS, defendem o uso das } \\
\text { mamadeiras somente para as } \\
\text { mães que trabalham. }\end{array}$ & $\begin{array}{l}\text { Apesar de conhecerem os malefícios do } \\
\text { uso de mamadeiras, a maior parte das } \\
\text { mães tentou dar ou deu este objeto ao } \\
\text { bebê. } \\
\text { Os motivos para a utilização de } \\
\text { mamadeiras estavam relacionados à } \\
\text { introdução de outro leite na alimentação } \\
\text { do bebê, justificada pelo "leite } \\
\text { insuficiente, pouco leite" ou "leite năo } \\
\text { sustenta". }\end{array}$ \\
\hline $\begin{array}{l}\text { Opinião sobre a } \\
\text { utilização de } \\
\text { água e chá }\end{array}$ & $\begin{array}{l}\text { Desnecessários, pois o leite } \\
\text { materno supre toda necessidade } \\
\text { hídrica do bebê. }\end{array}$ & $\begin{array}{l}\text { A maioria dos profissionais } \\
\text { relata que a mãe pode oferecer } \\
\text { água e chá para a criança, pois } \\
\text { estes líquidos não fazem mal à } \\
\text { saúde do bebê. } \\
\text { Ressalta-se que principalmente } \\
\text { o uso de chá nos casos em que } \\
\text { a criança apresenta dor de } \\
\text { barriga é visto com bons olhos } \\
\text { pelos ACS. }\end{array}$ & $\begin{array}{l}\text { Apesar de serem orientadas pelos } \\
\text { profissionais de saúde para não oferecer } \\
\text { água e chá ao bebê até o seis meses, a } \\
\text { maioria das mães deu estes líquidos ao } \\
\text { seu filho alegando que a criança poderia } \\
\text { estar com sede, devido ao calor (no caso } \\
\text { da água) ou dava para sanar as dores de } \\
\text { barriga, gases ou mesmo acalmar o bebê } \\
\text { (no caso do chá). }\end{array}$ \\
\hline Leite fraco & $\begin{array}{l}\text { A maioria não acredita na } \\
\text { existência do leite fraco - o leite } \\
\text { humano contém todos os } \\
\text { nutrientes que a criança precisa. }\end{array}$ & $\begin{array}{l}\text { A maioria não acredita na } \\
\text { existência do leite fraco - o leite } \\
\text { humano contém todos os } \\
\text { nutrientes que a criança } \\
\text { precisa. }\end{array}$ & $\begin{array}{l}\text { Ressalta-se que durante a lactação } \\
\text { algumas mães tiveram dúvida sobre a } \\
\text { qualidade do seu leite, mas estas } \\
\text { procuraram os profissionais do PSF, com o } \\
\text { intuito de esclarecer esta questão. Nestes } \\
\text { casos, os profissionais afirmaram que não } \\
\text { existe leite fraco. }\end{array}$ \\
\hline $\begin{array}{l}\text { Leite } \\
\text { insuficiente }\end{array}$ & $\begin{array}{l}\text { A maioria acredita que todas as } \\
\text { mães são capazes de produzir } \\
\text { leite na quantidade adequada } \\
\text { para o seu bebê. }\end{array}$ & $\begin{array}{l}\text { A maioria acredita que todas as } \\
\text { mães são capazes de produzir } \\
\text { leite na quantidade adequada } \\
\text { para o seu bebê. } \\
\text { Alguns profissionais } \\
\text { responsabilizam a mãe quando } \\
\text { esta relata que não consegue } \\
\text { produzir o leite na quantidade } \\
\text { adequada. }\end{array}$ & $\begin{array}{l}\text { A maior parte das mulheres entrevistadas } \\
\text { acredita que algumas mães são } \\
\text { desprovidas da capacidade de produzir } \\
\text { leite na quantidade necessária para seu } \\
\text { bebê. } \\
\text { Através dos depoimentos podemos extrair } \\
\text { algumas representações relacionadas com } \\
\text { a quantidade de leite produzido e que } \\
\text { podem levar ao desmame precoce, tais } \\
\text { como: "leite secou", "pouco leite", "leite } \\
\text { não sustenta". }\end{array}$ \\
\hline $\begin{array}{l}\text { Orientaçőes } \\
\text { durante o pós- } \\
\text { natal }\end{array}$ & $\begin{array}{l}\text { Orientam sobre a importância do } \\
\text { aleitamento materno exclusivo } \\
\text { até os seis meses. } \\
\text { Orientam sobre a posição e os } \\
\text { benefícios da lactação. } \\
\text { Orientam a realização do teste do } \\
\text { pezinho. } \\
\text { Orientam sobre os cuidados com } \\
\text { o bebê, principalmente em } \\
\text { relação ao umbigo. }\end{array}$ & $\begin{array}{l}\text { Aspecto não abordado no } \\
\text { grupo focal }\end{array}$ & $\begin{array}{l}\text { Os profissionais do PSF incentivavam as } \\
\text { mulheres a amamentar seus filhos, } \\
\text { principalmente até os seis meses de } \\
\text { maneira exclusiva. } \\
\text { Os profissionais ensinavam como iniciar a } \\
\text { introduçăo de novos alimentos na dieta do } \\
\text { bebê. }\end{array}$ \\
\hline
\end{tabular}


Analisando as queixas das mulheres no pós-parto e as orientações fornecidas nesta fase de vida da mulher-mãe (tabela 1), observa-se uma incoerência entre o discurso dos profissionais coimbrenses e a realidade materna. Apesar de o profissional de saúde conhecer e relatar as queixas, dúvidas e anseios da mulher-mãe, os resultados deste estudo apontam para a existência de um grande fosso entre o conhecimento relatado pelo profissional e a práxis cotidiana do serviço de saúde, já que em suas orientações estes não contemplam as reais necessidades da mulher-mãe.

As práticas dos profissionais entrevistados se reduzem às açōes de ordem biológica e aos procedimentos de rotina, resultados estes semelhantes ao encontrados por Ramos e Almeida (2003), os quais verificaram que apesar de os profissionais identificarem os anseios da nutriz, sua prática assistencial ainda encontrava-se enraizada no higienismo e no biologisismo.

Segundo Silva (2000, p. 368), "reduzir a experiência de amamentar ao modelo biológico e altruísta não contempla as possibilidades de atuação do profissional, pois não reflete o processo de amamentar do ponto de vista da mulher, que é, em última análise, quem toma as decisões e o rumo do aleitamento”. Monteiro (2000) ressalta, ainda, que a capacidade do profissional de saúde de ouvir a mulher, independentemente de seu estado fisiológico, através de uma escuta ativa e sensível, é determinante para uma prática assistencial capaz de solucionar os problemas da nutriz. Para Arantes (1995), o encontro entre o profissional e a mulher-mãe deve valorizar o olhar da protagonista sobre essa prática.

A análise da tabela 1 aponta ainda para a divergência entre as respostas dos profissionais e das nutrizes, assim como entre os próprios profissionais, evidenciando a presença de um discurso contraditório no que toca à amamentação, destacandose o uso de chupetas e mamadeira e a introdução precoce de chá e água. Observaram-se, também, incoerência das ESF quanto ao estabelecimento de prioridades relativas às orientações, as quais não contemplam possíveis motivos para o desmame, como: "leite secou", "leite insuficiente, pouco leite", "leite não sustenta", "leite não mata a sede do bebê", dentre outros - representaçôes estas encontradas nos depoimentos das mães coimbrenses.

Em relação aos resultados expostos na tabela 1, sugere-se que a opinião dos profissionais sobre o aleitamento materno, principalmente a visão da amamentação como dever materno, poderia ter influenciado o aparecimento de sentimentos de frustração e/ou de culpa nas mulheres-mães coimbrenses 
que não conseguiram amamentar. Segundo Gusman (2005), tanto os profissionais de saúde, a família, a sociedade, quanto a mulher-mãe, cobram responsabilidade perante o aleitamento, de maneira que a lactante tem que fazer a escolha correta em relação à alimentação do filho - não lhe sendo conferido o direito de errar. Sendo assim, o valor sociocultural do aleitamento materno faz com que a lactante sinta-se pressionada a amamentar, de modo que quando esta prática não é possível, a mãe passa a sentir-se culpada por não ter conseguido exercer completamente seu dever materno. Tais discrepâncias apontam para a necessidade de que o profissional de saúde conheça intimamente o contexto no qual a mulher que amamenta está inserida, bem como os símbolos significantes que as mães utilizam na decisão de amamentar.

Outro ponto que merece destaque na tabela 1 é que tanto no discurso da nutriz quanto no dos profissionais de saúde, pode-se observar a presença de mitos e crenças em relação à amamentação ("leite secou", "leite insuficiente, pouco leite", dentre outros), ao uso de chupetas e mamadeiras ("chupeta acalma, acalenta o bebê", "leite não sustenta", etc.), bem como o uso de chás ("leite não mata a sede do bebê", dentre outros). Este resultado reitera o fato de que da mesma forma que a nutriz constrói seu conceito de aleitamento materno através do seu contexto sociocultural, os profissionais de saúde também constroem sua assistência à lactante baseando-se nos significados que atribuem ao aleitamento materno (SILVA, 2001).

É importante frisar que os profissionais configuram-se como elementoschave a favor do aleitamento materno perante as mulheres-mães, pois estas necessitam de um atendimento especializado capaz de auxiliá-las no processo de amamentar, de maneira a superar os obstáculos vivenciados no decorrer do aleitamento (ARAÚJO; ALMEIDA, 2007).

\section{Conclusão}

Neste estudo procurou-se - a partir da apreensão dos depoimentos dos profissionais de saúde - explorar aspectos que podem influenciar positiva ou negativamente o atendimento diferenciado ao grupo materno-infantil, de maneira a promover, proteger e apoiar o aleitamento materno. Sob essa lógica, observouse que os profissionais do PSF do município de Coimbra encaram o ato de amamentar como uma prática biológica focada no recém-nascido e de exclusiva responsabilidade da mulher-mãe. Esta concepção pode fazer com que a nutriz 
sinta-se pressionada pelos profissionais de saúde, gerando o sentimento de culpa e de frustração perante o insucesso da amamentação, o que foi observado no discurso das mães entrevistadas.

No que se refere às orientações dadas à mulher-mãe sobre o aleitamento materno, estas são, em sua maioria, reflexos do modelo biomédico e mecanicista, não contemplando aspectos sociais e culturais desta prática. Desde esta perspectiva, o presente estudo evidenciou, também, importantes divergências entre as falas dos profissionais e das nutrizes em relação ao aleitamento, discrepâncias estas que podem ser causa da interrupção precoce da amamentação. Isso aponta para a necessidade de capacitação destes profissionais, de modo a possibilitar o embasamento teórico sólido das suas ações, tornando-as mais eficazes em prol do aleitamento.

Neste sentido, revestem-se de fundamental importância as políticas de educação continuada e o papel das instituições de ensino como elementos-chave na capacitação em amamentação, de maneira a formar profissionais capazes de responder às demandas sociais, tomando decisões a favor do aleitamento dentro do cotidiano das Unidades de Saúde da Família.

\section{Referências}

ALMEIDA, J.A.G. Amamentação: um híbrido natureza-cultura. Rio de Janeiro: Fiocruz, 1999.

ARANTES, C.I.S. Amamentação: visão das mulheres que amamentam. J Pediatr, v. 71, n. 4, p. 195-202, 1995.

ARAÚJO, R.M.A.; ALMEIDA, J.A.G. Aleitamento materno: desafio de compreender a vivência. Rev. Nutrição, v. 20, n. 4, p. 431-438, 2007.

BARDIN, L. Análise de conteúdo. Lisboa: Ediçôes 70, 1977.

BECKER, D. No seio da família: amamentação e promoção da saúde no Programa de Saúde da Família. Dissertação (Mestrado em Saúde Pública) - Escola Nacional de Saúde Pública, Fiocruz, Rio de Janeiro, 2001.

BRASIL. Departamento de Atenção Básica. A regionalização e a atenção básica: desafios da NOAS-SUS 01/2001 e os instrumentos que oferece para reorganizar o sistema. Saúde Família, n. 4, p. 11-16, 2002a.

Pacto pela Saúde. Disponível em: http://portal.saude.gov.br/portal/saude/ area.cfm?id_area=1021. Acesso em: 12 ago. 2008a.

. Pesquisa Nacional de Demografia e Saúde da Criança e da Mulher: PNDS 2006. Brasília: Ministério da Saúde, 2008b. 
BRASIL. Política Nacional de Promoção da Saúde. Série: Pactos pela saúde 2006, v. 7. Brasília: Ministério da Saúde, 2006.

. Programa Saúde da Família - PSF. Brasília: Ministério da Saúde, 2001.

- Secretaria de Atenção à Saúde. Pré-natal e puerpério: atenção qualificada e humanizada manual técnico. Brasília: Ministério da Saúde, 2005.

. Secretaria de Política de Saúde. Organização Pan-Americana da Saúde. Guia alimentar para crianças menores de dois anos. Brasília: Ministério da Saúde, 2002b.

CALDEIRA, A.P. et al. Conhecimento e práticas de promoção do aleitamento materno em Equipes de Saúde da Família em Montes Claros, Minas Gerais, Brasil. Cad. Saúde Pública, v. 23, n. 8, p. 1965-1970, 2007.

CICONI, R.C.V.; VENÂNCIO, S.I.; ESCUDER, M.M.L. Avaliação dos conhecimentos de equipes do Programa de Saúde da Família sobre o manejo do aleitamento materno em um município da região metropolitana de São Paulo. Rev. Bras. Saúde Matern. Infant., v. 4, n. 2, p. 193-202, 2004.

GUSMAN, C.R. Os significados da amamentação na perspectiva das mães. 2005. 103p. Dissertação (Mestrado em Enfermagem em Saúde Pública) - Escola de Enfermagem de Ribeirão Preto, Universidade Federal de São Paulo, Ribeirão Preto, São Paulo, 2005.

INSTITUTO BRASILEIRO DE GEOGRAFIA E ESTATÍSTICA. Dados Populacionais - 2007. Disponível em: http://www.ibge.gov.br/cidadesat/default.php. Acesso em: 05 mai. 2008.

LANA, A.P.B.; LAMOUNIER, J.A.; CÉSAR, C.C. Impacto de um programa para a promoção da amamentação em um centro de saúde. J Pediatr, v. 80, n. 3, p. 235-240, 2004.

MINAYO, M.C.S. Avaliação por triangulação de métodos. Rio de Janeiro: Fiocruz, 2005.

. Ciência, técnica e arte: o desafio da pesquisa qualitativa. In: Pesquisa Social: teoria, método e criatividade. Petrópolis: Vozes, 1994. . O desafio do conhecimento: pesquisa qualitativa em saúde. São Paulo: Hucitec, 2006.

MONTEIRO, K.A. O nutricionista e a amamentação: formação e docência para uma prática profissional. 2000. 170 p. Dissertação (Mestrado em Saúde da Criança e da Mulher) - Instituto Fernandes Figueira, FIOCRUZ, Rio de Janeiro, 2000.

NAKANO, M.A.S. As vivências da amamentação para um grupo de mulheres: nos limites de ser "o corpo para o filho" e de ser "o corpo para si”. Cad. Saúde Pública, v. 19, supl. 2, p. 355-363, 2003. NAKANO, M.A.S. et al. O espaço social das mulheres e a referência para o cuidado na prática da amamentação. Rev. Latino-Am. Enferm., n. 15, v. 2, p. 230-238, 2007.

OLIVEIRA, M.I. 10 passos para Centros/Postos/Unidades de Saúde da Família. Disponível em: http://www.aleitamento.com/a_artigos.asp?id=1\&id_artigo=441\&id_subcategoria=2. Acesso em: 13 jun. 2008.

Physis Revista de Saúde Coletiva, Rio de Janeiro, 19 [ 2 ]: 439-455, 2009 
RAMOS, C.V.; ALMEIDA, J.A.G. Alegaçōes maternas para o desmame: estudo qualitativo. $J$ Pediatr, v. 79, n. 5, p. 385-390, 2003.

SILVA, C.F.; ARAÚJO, P.M.; BITTENCOURT, R.A. Aleitamento materno entre profissionais de saúde da família. Rev Enferm UFPE On Line, v. 2, n. 2, p. 171-6, 2008.

SILVA, I.A. Enfermagem e aleitamento materno: combinando práticas seculares. Rev. Esc. Enf., v. 34, n. 4, p. 362-369, 2000.

SILVA, I.A. O profissional re-conhecendo a família como suporte social para a prática do aleitamento materno. Fam. Saúde Desenv., v. 3, n. 1, p. 7-14, 2001.

SOUZA, E.R. et al. Construção dos instrumentos qualitativos e quantitativos. In: MINAYO, M.C.S. Avaliação por triangulação de métodos. Rio de Janeiro: FIOCRUZ, 2005.

SOUZA, L.M.B.M. "Promoção, Proteção e Apoio. ”Apoio? Representaçōes Sociais em Aleitamento Materno. Rio de Janeiro: Papel Virtual, 2004.

\section{Nota}

* Este estudo faz parte do projeto de pesquisa intitulado "Aleitamento materno: (re)pensando a importância das representaçôes sociais e da rede social no contexto local", financiado pela FAPEMIG, Processo ${ }^{\circ}$ CDS APQ-1536-5.01/07. 
Practices and perceptions about breastfeeding: consensus and dissensus in the daily care in a Family Health Unit

This study is based on a qualitative research, and has two objectives: to identify the importance of breastfeeding for professionals who work in the Family Health Program; and to highlight convergent and divergent themes concerning breastfeeding among health care professionals and mothers. For data collection, the semi-structured and focus group were used. The study involved 17 professionals working in basic health care units and 58 mothers of children under two years old in the city of Coimbra, Mina Gerais State. The most important outcomes were that breastfeeding was regarded as an obligation by mothers, that the speech refers to the importance of a professional trained in lactation. The discourse analysis also highlighted an imbalance between the knowledge reported by the professional and daily practice of the health service. In this sense, the importance of continuing and permanent education policies are key elements for training in breastfeeding, and are indicators of health planning actions.

> Key words: Breastfeeding, Nursing Mothers; Family Health Program. 